\title{
In situ synthesis of multi-walled carbon nanorings by catalytic chemical vapor deposition process
}

\author{
Sivamaran Venkatesan ${ }^{1}$ (i) $\cdot$ Balasubramanian Visvalingam ${ }^{1} \cdot$ Gopalakrishnan Mannathusamy $^{2}$. \\ Viswabaskaran Viswanathan ${ }^{3} \cdot$ A. Gourav Rao ${ }^{4}$
}

Received: 26 October 2018 / Accepted: 6 February 2019 / Published online: 20 February 2019

(C) The Author(s) 2019

\begin{abstract}
Carbon nanorings (CNRs) are found to be the most promising nanostructure for the application of nanoscale devices. The CNRs are synthesized by many post-treatment processes such as ultrasonication and acid treatment. The post-treatment process may alter the properties of the rings. Hence, in this investigation, an attempt has been made to synthesize multi-walled carbon nanorings in a single-step process (as-synthesized condition itself). The CNRs are synthesized by catalytic chemical vapor deposition process using $\mathrm{NiO} / \mathrm{Al}_{2} \mathrm{O}_{3}$ as catalyst material, and acetylene was used as the precursor gas. FESEM confirms the as-grown ring structure and HRTEM reveals the effect of the isolation process. The rings typically have thickness ranges from 7 to $17 \mathrm{~nm}$, and diameter ranges from 10 to $190 \mathrm{~nm}$. In addition, FTIR, Raman spectroscopy was used to evaluate the functionality and structure of the rings, respectively. The scientific justification behind the growth mechanism to the CNRs and open rings was discussed in this paper. The agglomerated morphology of catalyst particles has a significant effect on the growth of ring structure.
\end{abstract}

Keywords Carbon nanorings $\cdot$ Chemical vapor deposition $\cdot$ Multi-walled carbon nanotubes $\cdot$ Growth mechanism

Sivamaran Venkatesan

sivamaranv@gmail.com

Balasubramanian Visvalingam

visvabalu@yahoo.com

Gopalakrishnan Mannathusamy

mgkrishnan61@gmail.com

Viswabaskaran Viswanathan zeramist@yahoo.co.in

A. Gourav Rao

gouravdrdo@gmail.com

1 Centre for Materials Joining and Research (CEMAJOR), Department of Manufacturing Engineering, Annamalai University, Annamalai Nagar (P.O), Chidambaram, Cuddalore, Tamil Nadu 608 002, India

2 Department of Chemistry, Annamalai University, Annamalai Nagar (P.O), Chidambaram, Cuddalore, Tamil Nadu 608 002, India

3 VB Ceramic Research Centre (VBCRC), 27A, 14th Link Road, 3rd Cross, Nehru Nagar Industrial Estate, Kottivakkam, Chennai 600 041, India

4 Naval Materials Research Laboratory (NMRL), Shil Badlapur Rd., MIDC Area, Ambernath, Thane, Maharashtra 421506, India

\section{Introduction}

The field of nanotechnology has grown discernible, because of research that was undertaken in carbon nanotubes (CNTs), especially on synthesizing different allotropes of carbon nanomaterials, like carbon nanorings [1], carbon nanorods [2], carbon nanosphere [3], etc. Following CNTs, the single-walled carbon nanorings (SWCNRs) and multi-walled carbon nanorings (MWCNRs) are found to be the most interesting carbon nanostructure, since they are considered as the giant of all carbon structure and directly used as a nanoscale device [4]. Recently, several research groups have reported on modifying the as-synthesized CNTs into the formation of the ring-shaped carbon tube via post-treatment processes [5-7]. Mostly, the post-treatment process involves chemical treatment to bend the CNTs into the ring shape and structure, which might alter the essential characteristics of nanotubes [8]. To overcome these problems, it is, indeed, necessary to synthesize carbon nanorings (CNR) in the as-synthesized condition itself.

CNR can be synthesized by various methods, including laser growth [9], ultra-sonic bath [10], and chemical vapor deposition process $[8,11]$. Compared to the other methods, the chemical vapor deposition (CVD) process is capable of 
synthesizing CNR in a single step. However, in other processes, first, CNTs were synthesized, and then, tubes were subjected to an acid treatment to form rings [12]. Furthermore, the formation of rings in a chemical process may enhance the essential characteristics of the CNR.

Zhou et al. [5] have synthesized single-walled carbon nanorings (SWCNRs) in a floating catalyst chemical vapor deposition (FCCVD) process. FCCVD consists of two-furnace setup, where the catalyst was placed in the first furnace and the substrate was placed in the second furnace at $1100{ }^{\circ} \mathrm{C}$. Song et al. [13] have synthesized SWCNRs in a similar manner using a FCCVD process by ferrocene as a catalyst at $1100{ }^{\circ} \mathrm{C}$. A few researchers only have reported the synthesize of CNR via catalytic CVD $[11,14]$ process. There is a lack of information on the characteristics of the catalyst particles that were used to synthesize CNR, especially in catalytic chemical vapor deposition (CCVD) process.

Recently, Venkatesan et al. [15], optimized the CCVD parameters to synthesize well-aligned multi-walled carbon nanotubes (MWCNTs) using $\mathrm{Ni} / \mathrm{Al}_{2} \mathrm{O}_{3}$ as a catalyst material. It is believed that CNT bundles can be grown abundantly using agglomerated catalyst particles. Hence, in this investigation, an attempt has been made to synthesize CNRs via the CCVD process using agglomerated $\mathrm{NiO} / \mathrm{Al}_{2} \mathrm{O}_{3}$ as catalyst and acetylene as a precursor gas.

\section{Experimental}

The $\mathrm{NiO} / \mathrm{Al}_{2} \mathrm{O}_{3}$ catalyst was prepared by impregnation method as proposed by Kong et al. [16]. The final step of catalyst preparation, fine grinding, was avoided to achieve the agglomerated catalyst and to facilitate the formation of rings.

The MWCNTs were synthesized at atmospheric pressure in a quartz-tube reactor (diameter $70 \mathrm{~mm}$; length $300 \mathrm{~mm}$ ) by thermal chemical vapor deposition machine. The reaction temperature was kept at $900{ }^{\circ} \mathrm{C}$ and the acetylene was used as a precursor gas; flow rate was held at $180 \mathrm{ml} / \mathrm{min}$. After a growth period of $25 \mathrm{~min}$, the as-grown carbon samples were collected to characterize using a different image and analytical techniques. After FESEM analysis, the rings were extracted from the CNTs bundles by the strong HF acid treatment.

The as-grown CNR morphology was observed by the field-emission scanning electron microscopy (FESEM), with EDS. The structural and side wall defects of CNR were examined by high-resolution transmission electron microscopy (HRTEM). The structural quality and orientation of rings were analyzed by Laser Confocal Raman Spectrometer with Microscope. X-ray diffraction (XRD) analysis was carried out using Mini Flex 300/600—Benchtop X-ray diffractometer. The surface functionalization of rings was studied by Fourier transform infrared spectroscopy (FTIR).

\section{Results}

The morphology in shape and agglomerated of $\mathrm{NiO} / \mathrm{Al}_{2} \mathrm{O}_{3}$ catalyst particles is shown in Fig. 1a. The particles are spherical. Figure 1b shows EDAX analysis image of $\mathrm{NiO} /$ $\mathrm{Al}_{2} \mathrm{O}_{3}$ catalyst particles. Figure 2 shows the FESEM images of CNR at different magnifications and in different spots of the sample. Since no purification treatment was performed
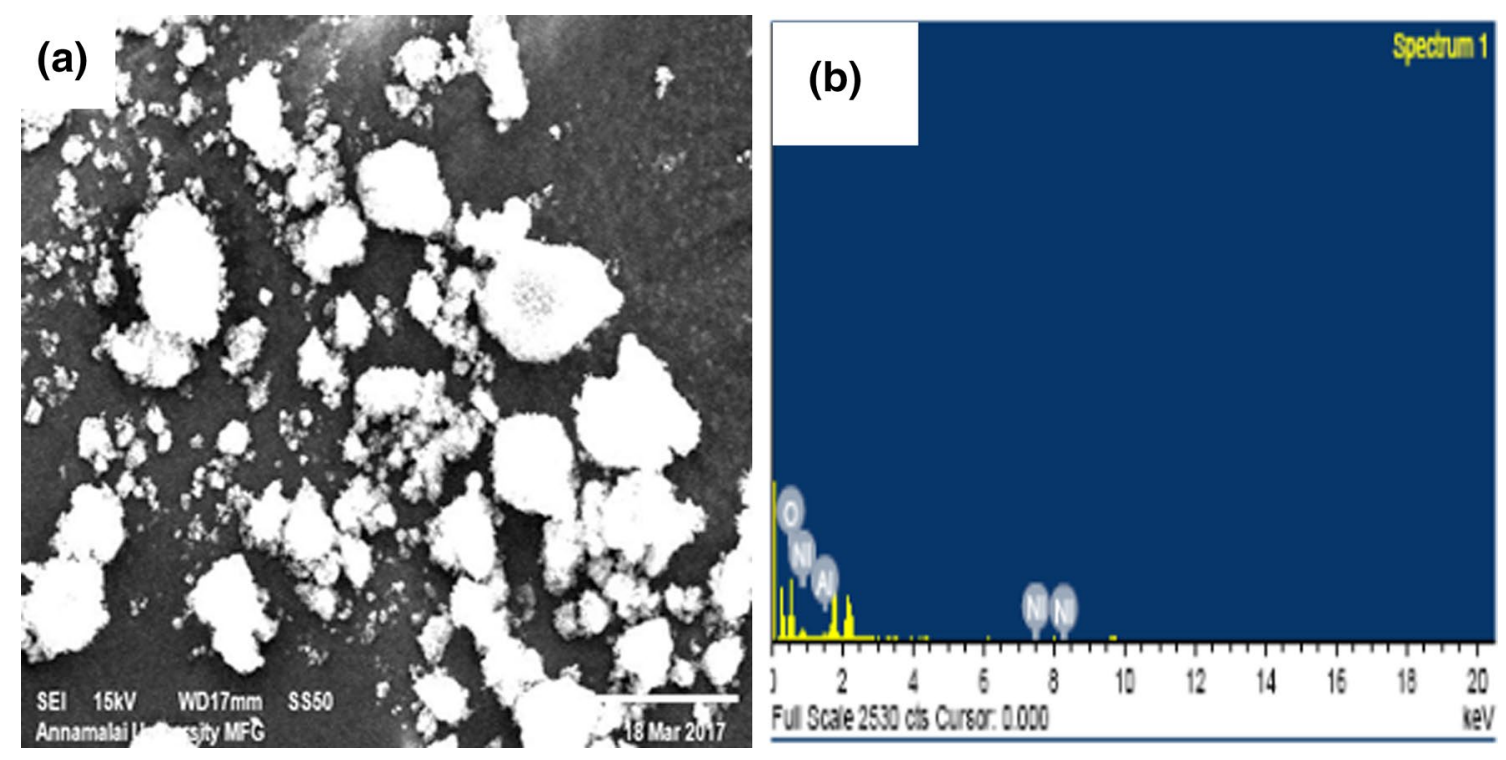

Fig. 1 a FESEM image of agglomerated $\mathrm{NiO} / \mathrm{Al}_{2} \mathrm{O}_{3}$ metal catalyst and $\mathbf{b}$ EDAX analysis image shows the presence of $\mathrm{Ni}, \mathrm{Al}$, and $\mathrm{O}$ elements 

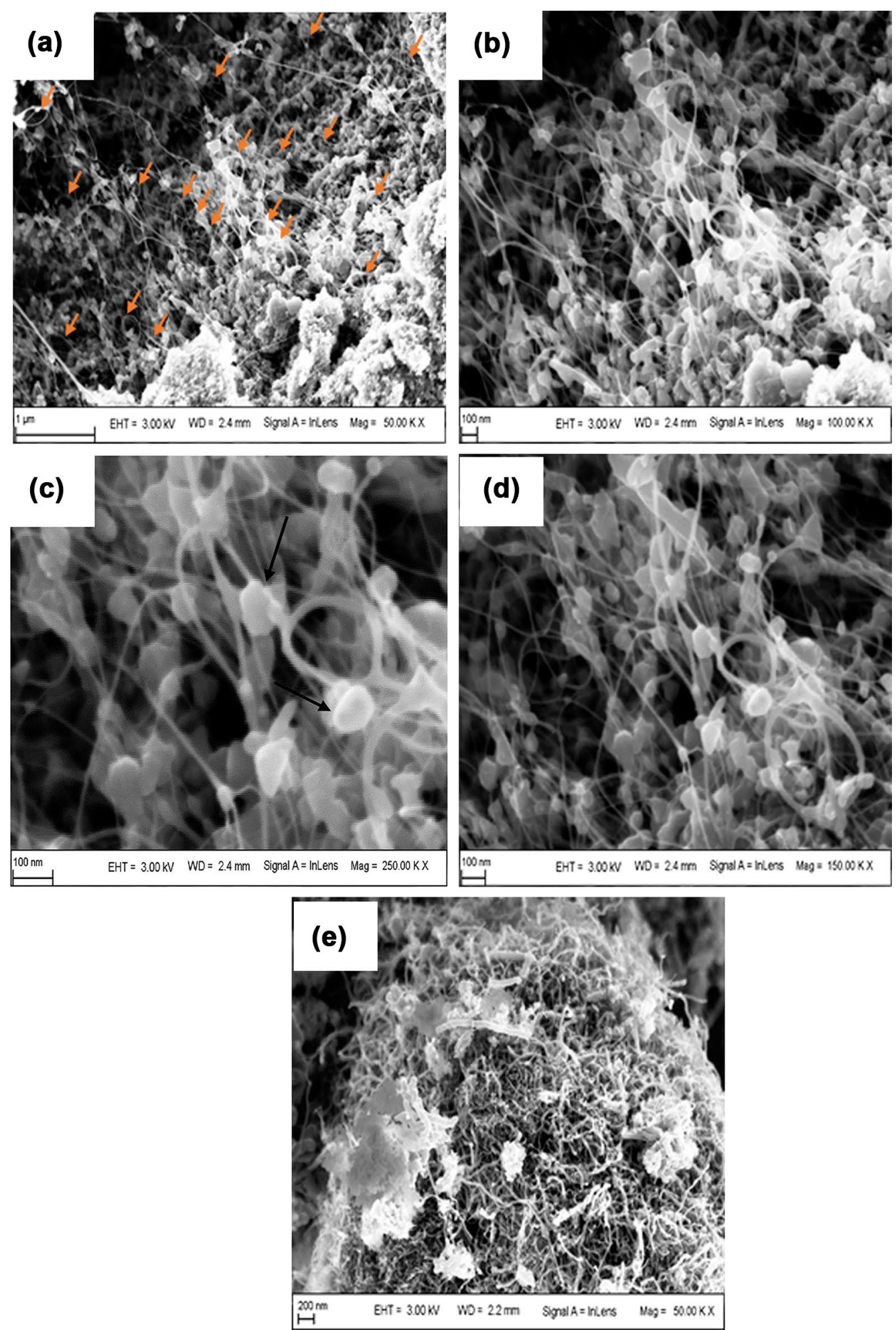

Fig. 2 FESEM image a-d CNRs image at different magnifications at various spots of the sample; $\mathbf{e}$ image of straight nanotubes synthesized at different CVD process conditions 
on the sample before the FESEM characterization, the CNR structure obtained are as-synthesized. Figure 2a clearly reveals that the high yield of CNRs as indicated by an arrow mark and some of the straight nanotubes are also observed in the sample. Figure $2 b$ shows the grown rings having a well-defined ring structure, along with rings. The CNTs, amorphous carbon, and catalyst particles are also present in the sample because of the as-grown samples which are not purified during FESEM analysis. Figure $2 \mathrm{c}$ is the higher magnification image of the Fig. 2b. It is clearly evident from this figure that straight nanotubes were connected to form the rings. The presence of a catalyst particle at the tip of the rings is indicated by an arrow mark. Hence, it is concluded that CNR was synthesized by tip-growth mode depicted in Fig. 2d.

There is no open literature available revealing the growth mode of CNR, especially in MWCNRs. The rings typically have thickness ranges from 7 to $17 \mathrm{~nm}$, and diameter ranges from 10 to $190 \mathrm{~nm}$. Ahlskog et al. [11] reported that CNR synthesized by CVD process has a thickness of 11-21 nm and a diameter of $400 \mathrm{~nm}$, which is larger than the results obtained in this investigation. Figure $2 \mathrm{e}$ shows the bundles of
CNTs synthesized at the flow rate of $140 \mathrm{ml} / \mathrm{min}$ precursor gas. The image $2 \mathrm{e}$ clearly shows the straight nanotubes and shows the presence of some of the curved nanotubes.

The HRTEM image of CNR is shown in Fig. 3. Most of the rings were fractured rings as shown in Fig. 3a, due to strong $\mathrm{HF}$ acid treatment procedure that was employed in the extraction step. Figure $3 \mathrm{~b}$ depicts the individual CNR with well-oriented structure. Figure $3 \mathrm{c}$ represents the ring, where the inner diameter and outer diameter of the rings were clearly visible and it could be confirmed as the MWCNR. The image $3 c$ also reveals the MWCNR with sidewall defects and the rings are buried under the amorphous carbon.

Raman spectroscopy analysis was employed on the MWCNRs mainly to study the structure and orientation of the rings. When CNTs is subjected to Raman spectroscopy analysis, usually, it consists of two main peaks: G and D bands. However, $\mathrm{G}$ band of ring shows new features compared to straight nanotubes, as shown in Fig. 4. The Raman spectra of $\mathrm{G}$ band were split into two components, i.e., $\mathrm{G}^{-}$and $\mathrm{G}^{+}$. The results of Raman spectra of the rings are matching with the work done by Ren et al. [17]. To analyze
Fig. 3 HRTEM images of openring MWCNTs
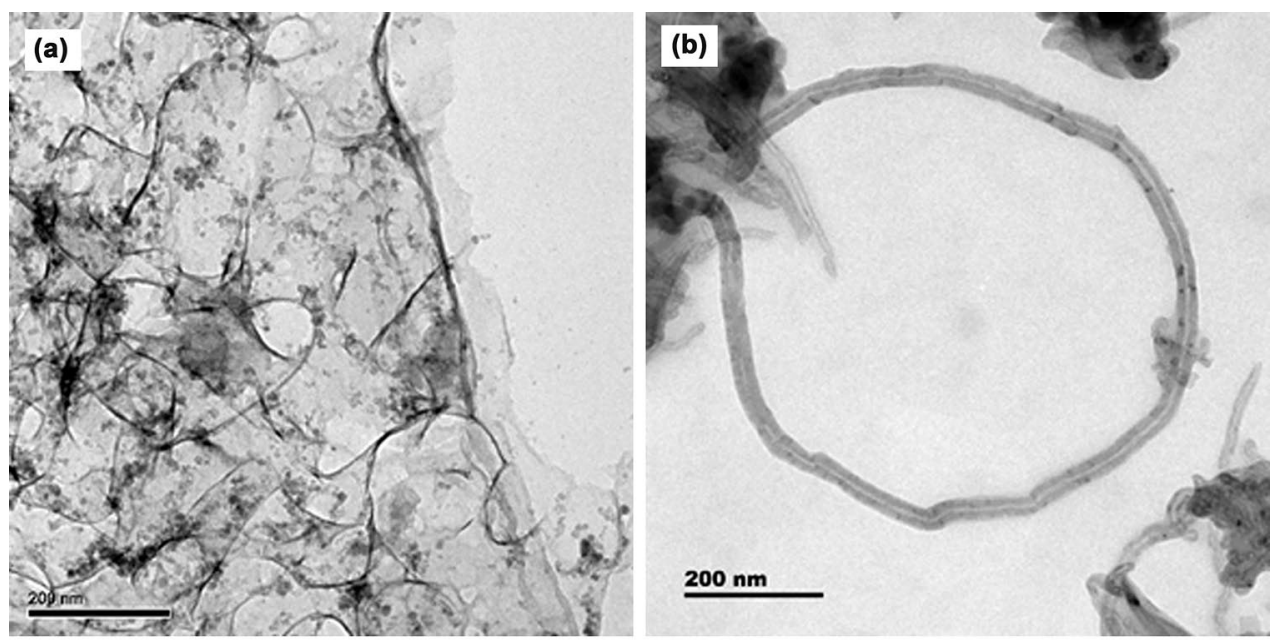

(c)

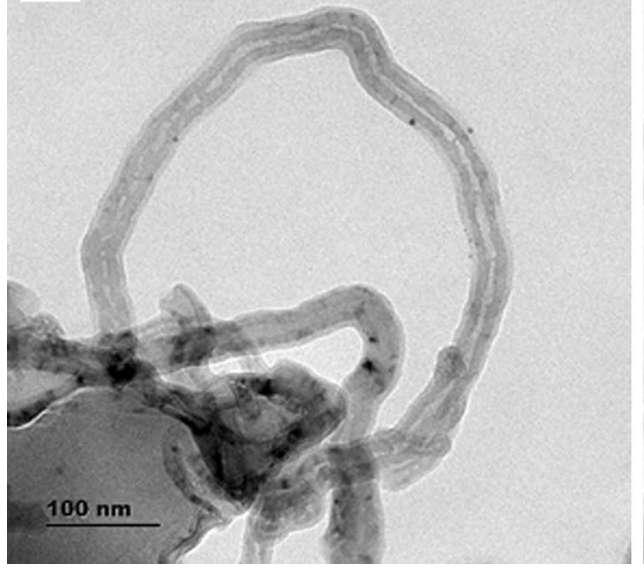


Table 1 Raman spectra analysis of CNRs peaks

\begin{tabular}{lllll}
\hline No & Band & Intensity & FWHM & $\mathrm{I}_{\mathrm{D}} / \mathrm{I}_{\mathrm{G}}$ RATIO \\
\hline 1. & $\mathrm{G}^{+}$ & $1594 \mathrm{~cm}^{-1}$ & $54 \mathrm{~cm}^{-1}$ & 1.56 \\
\hline
\end{tabular}

the $\mathrm{G}$ band peaks, the spectra was normalized to obtain the area, full width half maximum (FWHM), and peak intensity using Gaussian peak functions. The analysis was a failure due to the lower intensity of the $\mathrm{G}^{-}$band. However, $\mathrm{G}^{+}$band peak, which has a higher intensity, was analyzed and the obtained result is presented in Table 1. Wang et al. [18] synthesized SWCNRs using Pickering emulsion-based processes and the FWHM value was similar to this investigation. They obtained FWHM value in between 50 and $60 \mathrm{~cm}^{-1}$, for CNR diameter of 150-300 nm. Figure 4 also shows the Raman spectra peaks of the linear MWCNTs, which indicates the absence of G-band spectra.

XRD analysis of rings is shown in Fig. 5, which clearly reveals the amorphous nature of the sample after the HF acid treatment of the extraction process. The only observed peak was 21.73 theta. The MWCNTs' peak of 25.8 (002) (JCPDS card no. 26-1079) was proposed by Liu et al. [19], which is close to the rings XRD pattern of 21.73 theta. The diffraction angle $(d)$ and FWHM of XRD peaks of CNRs are calculated and presented in Table 2.

The FTIR spectra of MWCNRs in the range between 500 and $4000 \mathrm{~cm}^{-1}$ are shown in Fig. 6 . The $1658 \mathrm{~cm}^{-1}$ peak is attributed to the graphitic mode, and in between 830 and $930 \mathrm{~cm}^{-1}$, two sharp peaks are observed, which resemble the graphitic mode peak of $1658 \mathrm{~cm}^{-1}$. The peak at $1503 \mathrm{~cm}^{-1}$ is assigned to the $\mathrm{D}$ band. Taking consideration of the peak wavenumbers of Branca et al. [20], they depicted the FTIR results in oxidative nature of MWCNTs; compared to that FTIR peak, the peak of the rings is shifted up to higher wavenumbers.

\section{Discussion}

The MWCNR structure, analytical characterization, and functionalization are presented and discussed briefly in the results section. The first step of this investigation was to synthesize agglomerated catalyst. Song et al. [13] proposed that CNTs in bundles grow with different growth rates due to the different extrusion velocities of carbon atoms on the catalyst particles. It is believed that CNT bundles will curve due to the stress induced between the two nanotube walls inside the bundles. To enhance the bending moment of the CNT walls, the agglomerated catalyst was synthesized, which will facilitate the growth of two nanotube walls as far as nearer to each other. This reduction in space between the two nanotube walls promotes the curvy nature of CNTs. In this

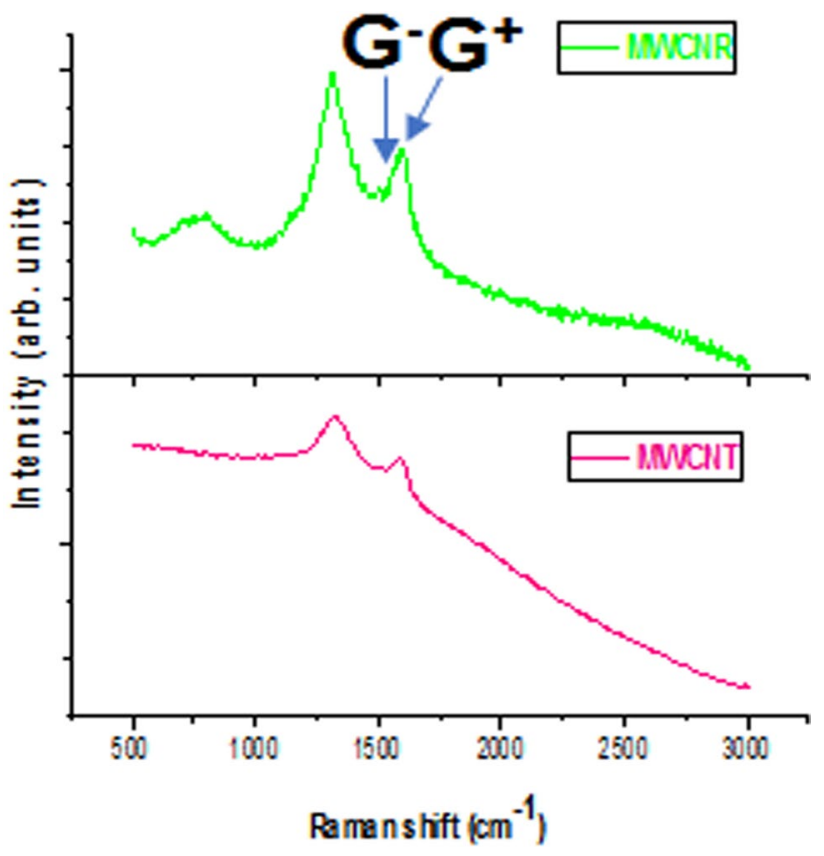

Fig. 4 Raman spectra of carbon nanorings (green peaks) and straight nanotubes (purple peaks)

Table 2 XRD peak results of CNRs

\begin{tabular}{lllll}
\hline No & 2-theta (deg) & D (ang.) & Height (counts) & FWHM (deg) \\
\hline 1. & 21.73 & 4.09 & 153 & 13.89 \\
\hline
\end{tabular}

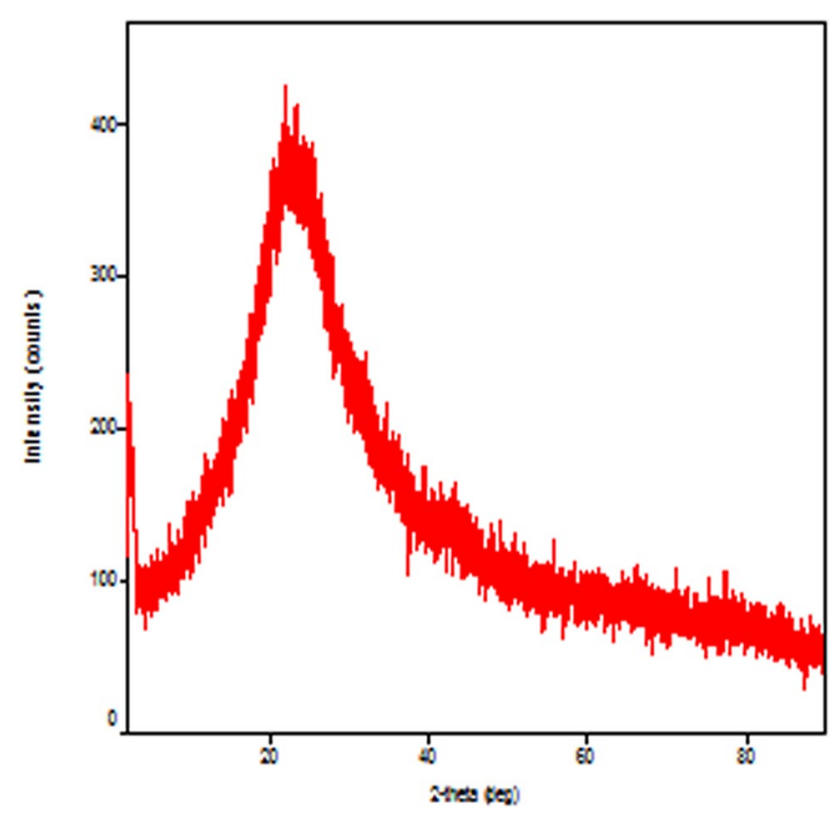

Fig. 5 XRD peak of carbon nanorings 


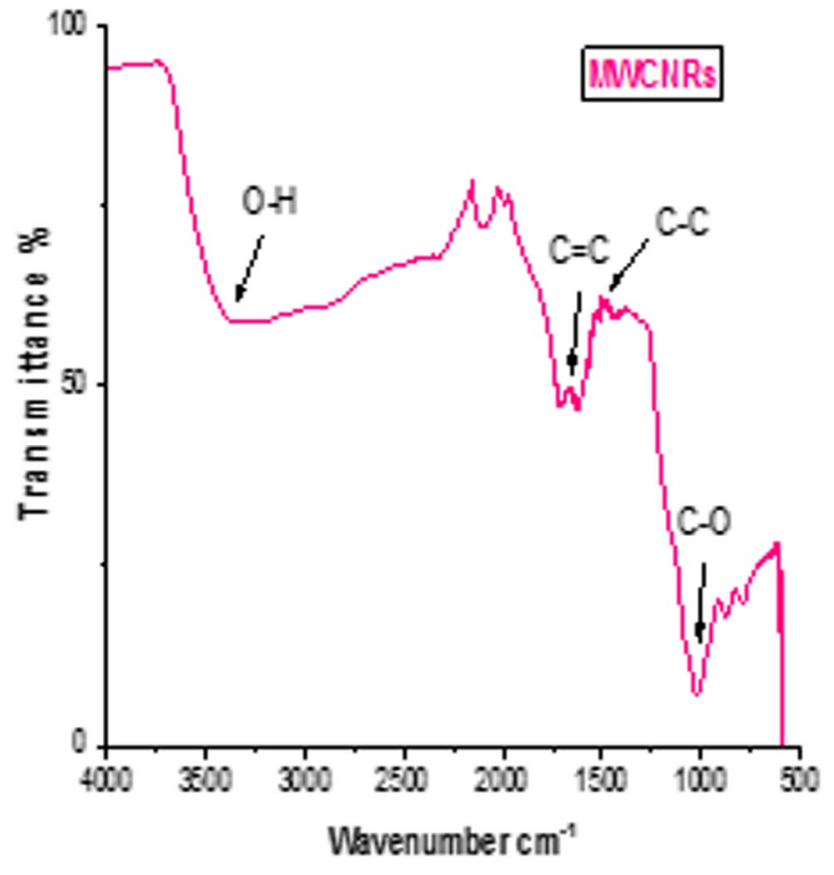

Fig. 6 FTIR peaks of carbon nanorings

investigation, it is found that the MWCNRs have grown as tip-growth mode. The growth of CNTs is mostly tip-growth mode in the catalytic CVD process.

The catalyst particles are in active mode at elevated temperature and at the flow of precursor gas, and the growth rate of nanotube varies with respect to the flow rate of precursor gas due to the different extrusion velocity of carbon atoms on the catalyst particles. This leads to the nanotube wall curve with each other, due to induced thermal stress. The catalyst particles are freely supported on the alumina boat, which facilitates to carry the particles at the tip of the nanotube.

The bending nature of the tube may be facilitated through these three mechanisms,

1. The stress induced between the two walls of nanotube that bend the tube into the toroidal structure.
2. The tip of the nanotubes should be weighed compared to the bottom due to the presence of catalyst particles and it led to the slope or bends the nanotubes, towards the flow direction of precursor gas.

3. Both the stress-induced curvature and bending due to the velocity of precursor gas along with a weighed tip of the tube occurs in a parallel way to enhance the curvature nature of the straight tubes.

The open ring of MWCNTs is shown in Fig. 3a. The formation mechanism for open-ring MWCNTs is depicted in Fig. 7. Figure 7a shows the active catalyst particle in an elevated temperature and the extrusion velocity of carbon atoms on catalyst varies with each particle in the substrate. This results in mismatch growth in nanotubes regarding the length of the nanotube walls, as depicted in Fig. 7c. The bending nanotube eating its own tail is depicted in Fig. $7 d$, though the nanotube tail is attached with the catalyst particles, which claim to be tip-growth mode of MWCNTs. While conducting the extraction treatment on the ring samples using HF acid, the catalyst particles are dissolved and result in open-ring MWCNTs, as shown in Fig. 7e.

Song et al. [21], studied the Raman spectroscopy on the SWNTs' rings, where the spectra split into several peaks. The Raman spectra obtained in this investigation are also split into more peaks (Fig. 4). The FTIR image (Fig. 6) shows a functional group attached with rings and peaks are shifted to higher wavenumbers due to the decrease in bond length. Since the curvature reduces the bond length of the tube which results in a higher shift in peak wavenumbers. Figure 2e shows the FESEM image of nanotubes synthesized at a flow rate of precursor gas $140 \mathrm{ml} / \mathrm{min}$, and it has abundant of the straight nanotube and there is no evidence of curved nanotubes. This effect clearly clarifies that extrusion of carbon atoms on catalyst particle variation is not influenced as much as compared to $180 \mathrm{ml} / \mathrm{min}$ precursor gas flow rate, which results in straight nanotubes. Hence, as anticipated by Song et al. [13], the flow rate of precursor gas has a significant effect on the curvature of CNTs.
Fig. 7 a-d Growth mechanism of carbon nanorings; e openring structure

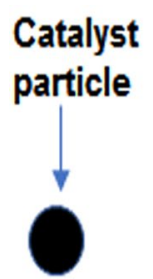

(a)

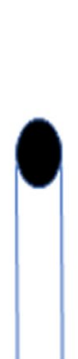

(b)

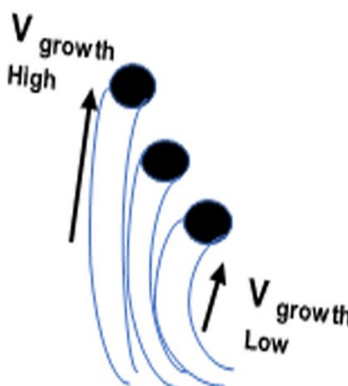

(c)

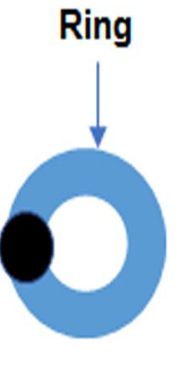

(d)

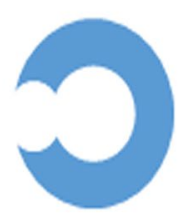

(e) 
Though Ko et al. [22] synthesized open-ring nanotubes by ultrasonication process, CCVD process employed in this investigation is also a viable route to synthesize open-ring MWCNTs and it will pave way for large-scale production.

\section{Conclusions}

(i) A new combination of agglomerated catalyst particles $\left(\mathrm{NiO} / \mathrm{Al}_{2} \mathrm{O}_{3}\right)$ has been synthesized to produce multi-walled carbon nanorings.

(ii) A new procedure has been developed to synthesize MWCNRs by thermally decomposing acetylene in a catalytic CVD process.

(iii) It is found that the flow rate of precursor gas has greater influence on the bending nature of nanotubes.

\begin{abstract}
Acknowledgements The first author gratefully acknowledges the financial support provided by M/s. VB Ceramics Consultants (VBCC) (Grant no. G8/83628/2015), Nehru Nagar Industrial Estate, Kottivakkam, Chennai-600041, India, through VBCRF (VB CERAMICS RESEARCH FELLOWSHIP). The authors are grateful to The Director, Naval Materials Research Laboratory (NMRL), DRDO, Ambernath, Maharashtra, for granting permission to utilize FESEM facility to characterize MWCNTs.
\end{abstract}

\section{Compliance with ethical standards}

Conflict of interest The authors declare that they have no conflict of interest.

Open Access This article is distributed under the terms of the Creative Commons Attribution 4.0 International License (http://creativeco mmons.org/licenses/by/4.0/), which permits unrestricted use, distribution, and reproduction in any medium, provided you give appropriate credit to the original author(s) and the source, provide a link to the Creative Commons license, and indicate if changes were made.

\section{References}

1. Sai Krishna, K., Eswaramoorthy, M.: Novel synthesis of carbon nanorings and their characterization. Chem. Phys. Lett. 433, 327 330 (2007). https://doi.org/10.1016/j.cplett.2006.11.068

2. Liu, Y., Hu, W., Wang, X., Long, C., Zhang, J., Zhu, D., Tang, D., Xie, S.: Carbon nanorods. Chem. Phys. Lett. 331, 31-34 (2000). https://doi.org/10.1016/S0009-2614(00)01143-X

3. Chen, L., Wang, H., Xu, J., Shen, X., Yao, L., Zhu, L., Zeng, Z.: Controlling reversible elastic deformation of carbon nanotube rings. J. Am. Chem. Soc. 133, 9654-9657 (2011). https://doi. org/10.1021/ja2022976

4. Liu, Y., Zhang, X., Chang, C., Zhang, D., Wu, Y.: Promotive effect of multi-walled carbon nanotubes on $\mathrm{Co}_{3} \mathrm{O}_{4}$ nanosheets and their application in lithium-ion battery. Prog. Nat. Sci. Mater. Int. 24, 184-190 (2014). https://doi.org/10.1016/j.pnsc.2014.05.001

5. Sun, J., Liu, H., Chen, X., Evans, D.G., Yang, W., Duan, X.: Carbon nanorings and their enhanced lithium storage properties.
Adv. Mater. 25, 1125-1130 (2013). https://doi.org/10.1002/ adma.201203108

6. Omachi, H., Segawa, Y., Itami, K.: Synthesis and racemization process of chiral carbon nanorings: a step toward the chemical synthesis of chiral carbon nanotubes. Org. Lett. 13, 1-4 (2011)

7. Feng, C., Liew, K.M.: A molecular mechanics analysis of the buckling behavior of carbon nanorings under tension. Carbon N. Y. 47, 3508-3514 (2009). https://doi.org/10.1016/j.carbo n.2009.08.021

8. Zhou, Z., Wan, D., Bai, Y., Dou, X., Song, L., Zhou, W., Mo, Y., Xie, S.: Ring formation from the direct floating catalytic chemical vapor deposition. Phys. E. 33, 24-27 (2006). https:// doi.org/10.1016/j.physe.2005.10.016

9. Liu, J., Dai, H., Hafner, J.H., Colbert, D.T., Smalley, R.E.: Fullerene "crop circles". Nature 385, 780-781 (1997). https://doi. org/10.1038/385780b0

10. Wang, W., Laird, E.D., Gogotsi, Y., Li, C.Y.: Bending singlewalled carbon nanotubes into nanorings using a Pickering emulsion-based process. Carbon N. Y. 50, 1769-1775 (2012). https:// doi.org/10.1016/j.carbon.2011.12.024

11. Ahlskog, M., Seynaeve, E., Vullers, R.J.M., Van Haesendonck, C., Fonseca, A., Hernadi, K., Nagy, B.: Ring formations from catalytically synthesized carbon nanotubes. J. Chem. Phys. Lett. 300, 202-206 (1999). https://doi.org/10.1016/S0009-2614(98)01322-0

12. Masahito, S., Ayumi, K., Junko, O., Seiji, S.: Ring closure of carbon nanotubes. Science 293, 1299-1301 (2001)

13. Song, L., Ci, L., Sun, L., Jin, C., Liu, L., Ma, W., Liu, D., Zhao, X., Luo, S., Zhang, Z., Xiang, Y., Zhou, J., Zhou, W., Ding, Y., Wang, Z., Xie, S.: Large-scale synthesis of rings of bundled single-walled carbon nanotubes by floating chemical vapor deposition. Adv. Mater. 18, 1817-1821 (2006). https://doi.org/10.1002/ adma.200502372

14. Wang, X., Wang, Z., qi Liu Y, Wang C, Bai C, Zhu D, : Ring formation and fracture of a carbon nanotube. Chem. Phys. Lett. 339, 36-40 (2001). https://doi.org/10.1016/S0009-2614(01)00291-3

15. Sivamaran, V., Balasubramanian, V., Gopalakrishnan, M., Viswabaskaran, V., Gourav Rao, A.: Effect of chemical vapor deposition parameters on the diameter of multi walled carbon nanotubes. Int. Nano Lett. 8, 297-308 (2018). https://doi.org/10.1007/s4008 9-018-0252-4

16. Kong, J., Cassell, A.M., Dai, H.: Chemical vapor deposition of methane for single-walled carbon nanotubes. Chem. Phys. Lett. 292, 567-574 (1998). https://doi.org/10.1016/S0009 -2614(98)00745-3

17. Ren, Y., Song, L., Ma, W., Zhao, Y., Sun, L., Gu, C., Zhou, W., Xie, S.: Additional curvature-induced Raman splitting in carbon nanotube ring structures. Phys. Rev. B Condens. Matter Mater. Phys. 80, 1-4 (2009). https://doi.org/10.1103/PhysRevB.80.11341 2

18. Wang, W., Laird, E.D., Gogotsi, Y., Li, C.Y.: Bending singlewalled carbon nanotubes into nanorings using a Pickering emulsion-based process. Carbon N. Y. 50(5), 1769-1775 (2012). https ://doi.org/10.1016/j.carbon.2011.12.024

19. Liu, L., Liu, F., Zhao, J.: Curved carbon nanotubes: from unique geometries to novel properties and peculiar applications. Nano Res. 7, 626-657 (2014). https://doi.org/10.1007/s1227 4-014-0431-1

20. Branca, C., Frusteri, F., Magazu, V., Mangione, A.: Characterization of carbon nanotubes by TEM and infrared spectroscopy. J. Phys. Chem. B 108, 3469-3473 (2004). https://doi.org/10.1021/ jp0372183

21. Song, L., Ma, W., Ren, Y., Zhou, W., Xie, S., Tan, P., Sun, L.: Temperature dependence of Raman spectra in single-walled carbon nanotube rings. Appl. Phys. Lett. 92, 1-4 (2008). https://doi. org/10.1063/1.2891870 
22. Ko, W.Y., Su, J.W., Guo, C.H., Fu, S.J., Hsu, C.Y., Lin, K.J.: Highly conductive, transparent flexible films based on open rings of multi-walled carbon nanotubes. Thin Solid Films 519, $7717-$ 7722 (2011). https://doi.org/10.1016/j.tsf.2011.05.064
Publisher's Note Springer Nature remains neutral with regard to jurisdictional claims in published maps and institutional affiliations. 